Journal of Social Sciences (COES\&RJ-JSS)

ISSN (E): 2305-9249 ISSN (P): 2305-9494

Publisher: Centre of Excellence for Scientific \& Research Journalism, COES\&RJ LLC

Online Publication Date: $1^{\text {st }}$ April 2017

Online Issue: Volume 6, Number 2 Special, April 2017

http://centreofexcellence.net/J/JSS/JSS\%20Mainpage.htm

\title{
Improving students van Hiele and proof-writing ability using Geometer's sketchpad \\ Wenceslao A. Coronado
}

Mindanao State University, Naawan, Misamis Oriental, Philippines

Charita A. Luna - Professor

Mindanao University of Science and Technology

Cagayan de Oro City, Philippines

Dennis A. Tarepe -Professor

Mindanao University of Science and Technology

Cagayan de Oro City, Philippines

\section{Abstract:}

This paper was undertaken to determine the Philippine Science High School-Central Mindanao Campus sophomore science students van Hiele levels of understanding and proof-writing ability as influenced by Geometers Sketchpad. The place of the study was conducted at Philippine Science High School Central Mindanao Campus, Baloi, Lanao del Norte during the third and fourth quarter period of the school year, 2010. The subjects were second year high school students comprising of three intact sections with a total population of forty-four (44). The research employed the one-shot pretest and posttest design. The van Hiele geometry test and sets of proof-writing problems were administered, before using the Geometer's Sketchpad software. The same test instruments were administered after the treatment and the posttest score were considered as criterion measure. The frequency distribution of students van Hiele levels of understanding before and after using the Geometers Sketchpad revealed that majority of the students improved their knowledge in the subject from abstract level of thinking to deductive level thinking. The t-test of independence showed the following results: (1) There is significant difference between pretest and posttest on the student's van Hiele levels of understanding as influence by Geometer's Sketchpad; (2) There is significant difference between pretest and posttest on the student's proof-writing test as influence by Geometer's Sketchpad.

Keywords:

Geometer's sketchpad, Van Hiele levels of understanding and proof-writing in geometry, proof by contradiction, direct proof

Citation:

Coronado, Wenceslao A.; Luna, Charita A.; Tarepe, Dennis A. (2017); Improving Students van Hiele and Proof-writing ability using Geometer's sketchpad; Journal of Social Sciences (COES\&RJ-JSS), Vol.6, No.2 Special, pp: 55-74. 


\section{Introduction}

Helping students develop a high level of mathematical proficiency and critical thinking are important than ever before. These kinds of mathematical abilities that students need today-that adult citizen need goes far beyond what once was sufficient (Seeley, 2004). These call for an effective teacher who has a well developed, specialized content knowledge (SCK), and grounded on the knowledge on how to teach mathematics. He must also be equipped with the knowledge how to use technology to enhance student learning.

Student high level of mathematical thinking can be developed in the study of geometrywhether taught alone or integrated into other courses. Geometry strengthens the habit of mind that student will need as users of mathematics and as lifelong learners. It engages them to do reasoning, making sense of relationship, modeling and mathematical proof (Day, 2009). Developing students' ability to do mathematical proof and reasoning has long been a fundamental goal of mathematics education (Fitzgerald, 1996; Ross, 1998). In fact the National Council of Teachers of Mathematics (NCTM, 1989) declares "mathematics is reasoning", because if reasoning is not developed in the students then mathematics is simply mimicking without thoughts (Ross, 1998). Realizing mathematical proof and reasoning is one of the objectives in geometry course. Teachers play a critical role in the development of student mathematical thinking. He is responsible in providing the scaffoldings in the teaching-learning process so that learning will easily take place (Knight, 2006). The development of logical reasoning and proof-writing in geometry is one of the important tasks of the teacher. However it is one of the most difficult processes to teach because students like to abhor the skill. Teachers need some scaffolding which may arise interest the students through the use of technology. This difficulty in geometry is not only true in ordinary secondary schools of the Philippines but also the students of Philippine science high school in Central Mindanao who are scholars.

The Philippine government expects that graduates of this science high school will take the leadership in science and technology hence it is the duty of the mathematics teacher to help develop the maximum potential of the students through the aid of Geometers Sketchpad as the technology to enhance learning. The Geometer's Sketchpad (GSP) is a computer software which enables students to create drawings, make measurements, and drag a drawing which can visualize relationship (Jackiw, 2001). It also allows the students to explore mathematical properties, patterns, visualize models, enrich quality of investigation and promote mathematical ideas from multiple perspectives. The influence of Geometer's Sketchpad as technology scaffoldings to enhance van Hiele levels of understanding in geometry and geometry performance needs verification. Hence, the study sought to answer the following questions;

1. What are the students van Hiele levels of understanding and proof-writing ability in geometry before and after the use of Geometers Sketchpad?

2. How do the Geometers' Sketchpad influence the students van Hiele levels of understanding and proof-writing ability in geometry?.

\section{Methodology}

The researcher used three (3) intact classes of second year high school students with a total population of forty-four (44). The research employed the one-shot pretest and posttest design. The van Hiele geometry test of twenty-five (25) items was used, 
copyrighted by Usiskin (1982) for the Cognitive Development and Achievement in Secondary School Geometry (CDASSG), and four (4) proving questions were administered, before using the Geometer's Sketchpad software. A trial version of the software was used in the class.

The researcher designed and constructed four (4) Geometer's sketchpad activities related to the topics and problem solving. One activity summarized all the topics included in the study. The content of the activity included mainly the following parts; construct, investigate and explore. The activities done by the researcher were presented to the panel of experts for face validation and readability purposes. The same test instruments were administered after the treatment and the posttest score were considered as criterion measure. The problems were taken from the topics; triangles and triangle inequalities, quadrilaterals and similarity that underwent for face validity of the experts. For the proving methods, the students were required to use the proof by contradiction introduced in (Mariotti et al., 1997; Mariotti, 2000) as cited in (Antonini, S. and Mariotti, M.A., 2006) and direct proof where we assume $p$, and then use the rules of inference, axioms, definitions, and logical equivalences to prove q. The rubric system of scoring for proofwriting tasks was patterned from the study of Canoy (2007) as follows: 0 point- no answer or the statements given are incorrect; 1 point- the statement is checked and the student write the assumption of the given conditions; 2 points - correct assumption of the given conditions and an additional correct implication (using the definitions or theorems) or correct statement is made; 3 points - correct assumption of the given conditions and at least two correct implications or additional correct statements (with examples or reconstructing the figures or visual representations) are made; 4 points-correct assumption of the given conditions, and correct and appropriate geometric principles and concepts are used, however, there is a failure to operate with them and finish the last argument to complete the proof; 5 points - a correct or complete proof is given.

The students' feedback on proof-writing tasks were written by them and copied by the researcher in their evaluation verbatimly. Students used combinations of bisayan, tagalog and english language.

\section{Results and Discussions \\ Students van Hiele levels}

Table 1 shows the frequency distribution of students van Hiele levels of understanding before and after using the Geometers Sketchpad. The table reveals that majority of the students' knowledge in geometry before the exposure to Geometer's Sketchpad in the van Hiele test belongs to the level of abstract thinking, 17 or $38.6 \%$. This level explains that students understanding in geometry had established interrelationships of properties within the given figures. Followed by 8 out of 44 or $18.2 \%$ of the students fall under analytic thinking where students can recognized figures and analyzed the component parts and properties without explanation. Ten (10) or $22.7 \%$ of the students got the score that fall under deductive level of thinking. This level further explains that ten (10) students understood geometry which they can make generalization from definitions, theorems and postulates. One (1) student got the score in the highest level which is rigorous level of thinking and was able to relate the concepts in the abstract manner without use of figures. Not one among the students got a score which belongs to the first level of the van Hiele levels of thinking, which is holistic thinking. This is commendable because they are scholars of Philippine Science High school and it is expected that they belong to the cream 
of the crop of secondary students of the Philippines. There were eight (8) students who do not belong to any van Hiele levels of thinking. The study of Senk (1989) is consistent with this result that not all students being subjected to van Hiele test instrument will fit in the van Hiele levels of thinking. She further observed that in her study students maybe stupid or not interested in the subject (Senk, 1989).

After exposure of Geometer's Sketchpad, 22 out of 44 or $50 \%$ of the students have improved their van Hiele levels of understanding from abstract level to deductive thinking. The results further explained that students thinking about geometry have established interrelationships of properties and characteristics within the figures given and were able to make generalization from the concepts such as definitions, theorems and postulates. The subjects were able to do synthesizing the geometry concepts with correct logical reasoning so they have reached this level of understanding. Twelve (12) or 27.3\% remain in the abstract level of thinking after exposure to Geometer's Sketchpad. Three (3) or $6.8 \%$ of the students reached the highest level (rigorous thinking) and were able to compare different systems or situations in the problem solving and able to relate the concepts in abstract manner without use of figures. It can be noted further that in the posttest, $84.10 \%$ of the students reached at least level 2 (abstract to rigorous thinking). This observation is contrary to the result of Tan (2008), where she conducted a study to one of the laboratory science high school sophomore students' located in Central Mindanao University, Mindanao, Philippines. Her result revealed that majority of the students did not reach level 2 which is the abstract thinking. The result is not consistent with this study, maybe because in this study the researcher employed the Geometer's Sketchpad as the treatment but in her study the used of the technology or Geometer's Sketchpad was not present in her geometry instruction. Moreover, in the posttest $9.1 \%$ or 4 students remained under the level of analytic thinking. Three (3) of the subjects have scores that could not still fit to the van Hiele even after exposure to Geometer's Sketchpad.

Table 1. Frequency Distribution of Students van Hiele Levels of Understanding Before and After Using the Geometers Sketchpad

\begin{tabular}{|c|c|c|c|c|c|c|c|c|c|}
\hline \multirow{2}{*}{\multicolumn{2}{|c|}{$\begin{array}{c}\text { Van Hiele Level of } \\
\text { Understanding }\end{array}$}} & \multicolumn{4}{|c|}{ Pretest } & & \multicolumn{3}{|c|}{ Posttest } \\
\hline & & & freq & & $\%$ & & freq & & $\%$ \\
\hline$\overline{\text { Holistic }}$ & & 0 & & 0 & & 0 & & 0 & \\
\hline Analytic & 8 & & 18.2 & & 4 & & 9.1 & & \\
\hline Abstract & 17 & & 38.6 & & 12 & & 27.3 & & \\
\hline Deductive & & 10 & & 22.7 & & 22 & & 50.0 & \\
\hline Rigorous & & 1 & & 2.3 & & 3 & & 6.8 & \\
\hline Total & & 36 & & 81.8 & & 41 & & 93.2 & \\
\hline Missing (Not Fit) & & 8 & & 18.2 & & 3 & & 6.8 & \\
\hline
\end{tabular}


A comparison between pretest (blue bar) and posttest (green bar) van Hiele levels of understanding are shown in the bar graph in Figure 1, using the code name of the students and the van Hiele levels. Only thirty-four (34) students are included in the comparison because ten (10) students are classified as not fitted in the van Hiele levels. There are six (6) or 17.60 percent of the students where the van Hiele decreased by one level. This implies that there are students in the pretest who have reached the abstract thinking, but after the treatment, they have declined in their van Hiele level to analytic thinking, or some from deductive to abstract thinking. However, not one among the students declined from analytic to holistic thinking and none from rigorous to deductive thinking. On the other hand, among the 50 percent of the students there are those who jumped two steps higher than their previous levels and some only one step higher. That is, these increase of van Hiele levels explains that some students belong to analytic thinking have jumped to abstract thinking; or from abstract to deductive; or from deductive to rigorous thinking. Some have jumped also by two levels from analytic to deductive; or from abstract to rigorous thinking after the effect of the Geometer's Sketchpad. However, ten (10) or 29.41 percent of the students remains the same in spite of technology enhancement To cite a particular student say DF1 in the graph, she has a pretest van Hiele level 2 which is abstract. However, in the posttest, her van Hiele level is 3 which is deductive. She has increased by 1 step higher in the van Hiele level. Another student, DM7, he has shown consistent van Hiele levels both in the pretest and posttest, and has a score which is rigorous (level 4). Generally, based on the graph, majority of the students have improved their van Hiele levels of thinking in the posttest.

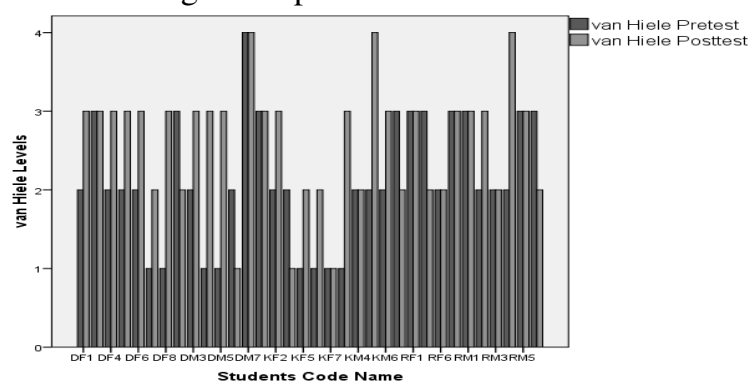

Figure 1. Comparison of van Hiele levels of students using the pretest and the posttest scores

Proof- writing of students using proof by contradiction with their feedback

Table 2 shows the students' first proof-writing task in angle sum inequality using proof by contradiction. The problems are shown in Appendix 1. It can be seen from the pretest results that many got 0 which is $40.9 \%$ and the one who gets 5 points is only $4.5 \%$. However, in the posttest only $9.1 \%$ has a score of 0 and $38.6 \%$ got a score of 2 and the same number of students has perfect score. This implies that there are two students who are really good in geometry and many are just average even if they are scholars. There are six students or $13.6 \%$ who has a score of 4 and this is a good sign that they have improved in their proving ability. Many of them could not answer correctly the assumption like saying, "Suppose $a+b \geq 180$ ". This result indicates that students have difficulty in proving. This implies further that teachers in mathematics need to cultivate the culture of proving whenever feasible. 
Considering the example of the pretest proof-writing using indirect method, the students were asked to prove "If the angles of a triangle measures as indicated below, then prove that $a+b<180$."

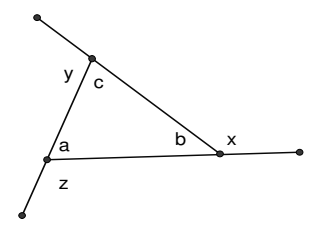

The proofs constructed by students DM1 in the pretest and posttest are shown in Figures 2 and 3, respectively. Student DM1 started his statement with an incorrect supposition. His statement was, "The sum of all angles of a triangle is 180 ", is an incorrect hypothesis for the indirect method of proof. Hence, a score of 0 out of 5 was obtained in the pretest. After exposure to Geometers Sketchpad his proof-writing ability increased to 2 out of 5 compared to 0 in the pretest. The student was able to write correct assumption that $a+b$ is not less than or equal to 180 which is equivalent to $a+b \geq 180$. But his next statement was incorrect because he assigned some particular values for two angles $a$ and

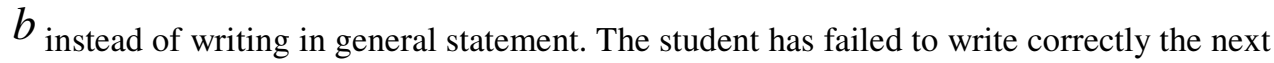
implication of his previous statement, although he had in mind to use the word contradiction at the end of his proof. Below was his declared feeling towards proofwriting task written in his evaluation.

"First gyud nako nga feeling sa Geometry kay murag makayakaya ra naku uy! (First I feel that I can pass the subject, oh!). Murag ang geometry kay perimeter, area, shapes and angles ra nga calculations (I was thinking that geometry were only simple calculations, like perimeter, area, solving angles and drawing shapes). Pero wala ko kabalo nga nay proving, nga bag-o nga mag-gamit ug definitions and theorems (But I don't know that there is proving, it's new to me to use definitions and theorems). First quarter pa nga topics ok ra, kaya ra (First quarter topics it's easy). Sa dihang mi abot ang proving, Oh my God! hay! (And then proving comes, oh my God! Makabuang gyud sya. Adtong panahona murag motoyuk ako panan-aw. (Proving makes me crazy, and I got double vision and out of focus.) Every test nga nay proving blurred na ako panan-aw ni Sir Omeng. (Every time that there is proving given in the test by my teacher, my vision is blurred, Hey!Hey!.) Kayanun nalang para mo survive (I will try my best to survive in the subject)". [DM1]

Table 2. Frequency distribution of the pretest and the posttest scores in proof- writing on angle sum-inequality

\begin{tabular}{|c|c|c|c|c|}
\hline \multirow[t]{2}{*}{ Score } & \multicolumn{2}{|c|}{ Frequency } & \multicolumn{2}{|c|}{ Percentage } \\
\hline & Pretest & Posttest & Pretest & Posttest \\
\hline 0 & 18 & 4 & 40.9 & 9.1 \\
\hline 1 & 17 & 14 & 38.6 & 31.8 \\
\hline 2 & 5 & 17 & 11.4 & 38.6 \\
\hline 3 & 1 & 1 & 2.3 & 2.3 \\
\hline
\end{tabular}


Improving Students van Hiele and Proof-writing ability ...

\begin{tabular}{lrrll}
4 & 1 & 6 & 2.3 & 13.6 \\
5 & 2 & 2 & 4.5 & 4.5 \\
Total & 44 & 44 & 100 & 100 \\
\hline
\end{tabular}

Another student RM4 proved the same problem as shown in Fig. 4. He got the correct assumption of the given and a score of 1 in the pretest. His posttest has shown much improvement in proof-writing as shown in Figure 5. A perfect score of 5 is evidenced in the correct and complete proof of the angle sum inequality. His improvement has some relation to his feeling towards the proof-writing task. The student was already aware that geometry was more on analysis, problem solving and proving tasks. He was also inspired from his teacher about values formation being shared by his teacher and a positive feeling was developed in his mind, particularly when his teacher also shared some jokes. His declared feeling towards proof-writing task was written in his evaluation as stated below.

"I feel already that the subject will be more proving tasks, solving and analysis. Besides learning this subject, we learn also about God by sharing the Holy Scriptures taken from the Bible by Sir Omeng shared. The subject is fun and we learn a lot of jokes from our teacher". [RM4]

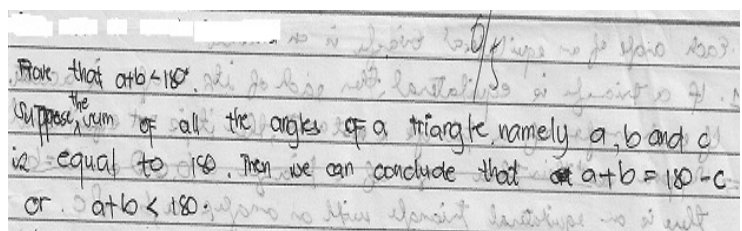

Figure 2: Proof of angle-sum inequality constructed by DM1 (pretest)

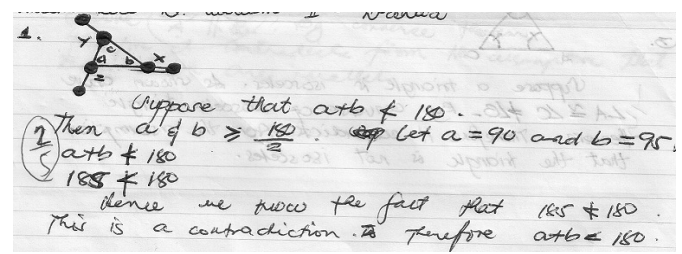

Figure 3: Proof of angle-sum inequality constructed by DM1 (posttest)

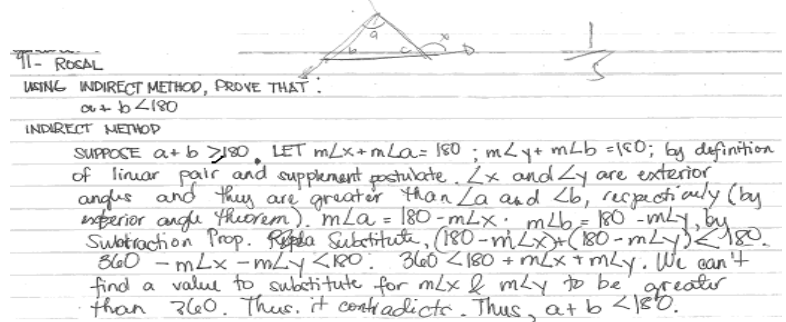

Figure 4: Proof of triangle-inequality constructed by student RM4 (pretest) 


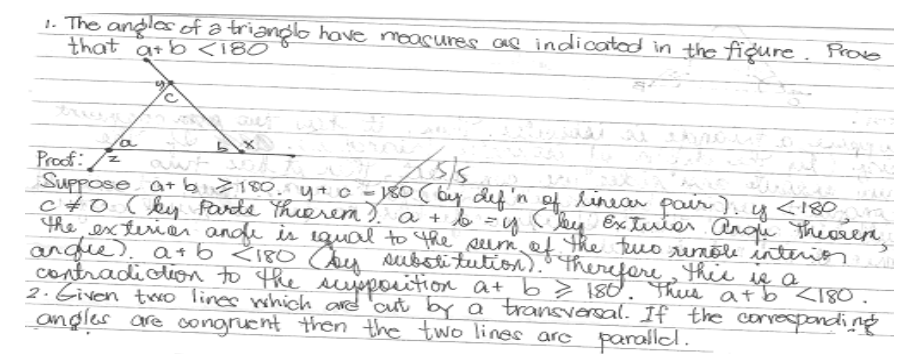

Figure 5: Proof of triangle-inequality constructed by student RM4 (posttest)

Additional evaluation on their feelings of the subject on the proof-writing tasks are derived from some of the students written responses as shown in the following:

"My feelings about the subject are to learn more and to gain knowledge. I thought that geometry is easy to pass and easy to understand because I love solving problems in Math but not proving “. [RF6]

"My feelings of the subject geometry were that it would be easy. Easy in a sense we would deal with shapes. But as our lessons became more complicated, my life did too. I never thought that we would deal more on proving. That was the only thing that my grades are low. I want more solving less proving" [RM1]

I feel that it would be easy like in grade school. Akala ko na itong subject na ito ay tungkol lang sa mga hugis (I was thinking that the subject will be dealing about shape). At sa pag compute ng area, perimeter at volume ng hugis. (And to compute the area, perimeter and volume) Pero sayup diay ko (But my feeling is wrong). Kani man diay na subject puro proving, hai! (This subject is more on proving, hai! student seems tired of doing proof.) Grabe man diay kalisud (It's too difficult). Perma lang ta mag nosebleed tungod sa mga ways kun unsaon pag prove (It seems like that my nose is bleeding, just to find ways how to prove). Abi gyud nako nga dali ra siya, sayup gyud diay ko (I was thinking that it's an easy subject, I'm wrong). Gagmay gyud ko ug grado kaau di ko kasabot (I got a low grade in this subject and I do not understand). Sa sinugdanan kay nadawat na nako ang mga topics pero pag abot sa tunga-tunga nagkalisud na tungod sa proving ( When I received the syllabus at the beginning of the class until the middle of the semester it was easy for me. But topics were becoming difficult when proving was introduced). Lahi ra gyud ako ginabati (My feeling was different, when there was already proving)". [DF6]

Based from the responses of the students' feelings toward proof-writing, the researcher has categorized their responses as either easy or difficult. Most of the students responded that they feel the subject easy. Their idea about easy, involves simple drawing of figures, simple recall of the formulas where the values are just substituted without much reasoning, just like the geometry subject in elementary grade. Other students responded that proof-writing is a difficult task. Their responses on their choice as difficult could have been influenced by the junior and senior students because they have experienced that geometry is difficult to comprehend, particularly on the proof-writing tasks.

The second students' proof-writing task is on isosceles triangle and the pretest and posttest results are presented in Table 3 . It can be gleaned from the pretest results that many get 0 , 
that is, 34 out of 44 or $77.3 \%$. The result implies that many students were not able to state or give the correct assumptions of the given problem. None among the students get a perfect score of five.

The proving ability of the students has improved after exposure to Geometer's Sketchpad. The posttest results indicate that only $18.2 \%$ gets 0 and $4.5 \%$ of the students gets a perfect. The majority $(29.5 \%)$ gets a score of 2 while $6.8 \%$ gets a score of 4 . The posttest results suggest that students' understanding in proof-writing tasks has improved in their logical reasoning because most of the students were able to come up with the correct assumptions and to give one or more implications of the given conditions.

Table 3. Frequency distribution of the pretest and posttest scores in proof-writing on isosceles triangle

\begin{tabular}{lcccc}
\hline Score & \multicolumn{2}{c}{ Frequency } & & \multicolumn{2}{c}{ Percentage } \\
& Pretest & Posttest & Pretest & Posttest \\
\hline & & & & \\
\hline 0 & 34 & 8 & 77.3 & 18.2 \\
1 & 6 & 9 & 13.6 & 20.5 \\
2 & 3 & 13 & 6.8 & 29.5 \\
3 & 1 & 6 & 2.3 & 13.6 \\
4 & 0 & 3 & 0 & 6.8 \\
5 & 0 & 2 & 0 & 4.5 \\
Total & 44 & 44 & 100 & 100 \\
& & & & \\
\hline
\end{tabular}

To analyze the proof constructed by some students, the students were asked to prove the statement, "If a triangle has no two congruent angles, then it is not isosceles". Figure 6 illustrates the proof constructed by student RF2 in the pretest. The student tried her best to establish the correct underlying proofs but no correct statement was written. The first line of her statement is "Given $\triangle A B C, \angle B \cong \angle C$, then it is isosceles" is just the negation of the statement given in the problem. Her assumption reads, "Given $\triangle A B C$, $\angle B \cong \angle C$ " and then she concluded that "a triangle is isosceles" which is incorrect.

The correct assumptions of the proof should be: "Suppose a triangle is isosceles". We may use definitions or theorems or other concepts to continue the implication of the assumption. Although she was able to relate the definition of the isosceles triangle and its implication, in general, her lines of proof are incorrect. Her posttest proof-writing task has shown improvement as reflected in Figure 7, and her score of 3 means that she started her proof correctly and with the correct implications. Her proof lacked other concepts to continue, and what to contradict was not clearly stated. Her initial reaction when she was asked to write her response to the statement, "Prove the following statements", was negative as shown below: 
“Aaaarrgghh! When I hear the statement, my smile turns upside down. I say in my mind, “Nah uie! Proving na pud ! (Proving again!). I never liked proving. I hate it! I hate it!, I hate it!, I hate it! Sorry Sir! Proving raman pud akong dili ganahan (Only the proving part I don't like). Okay man ang uban (I'm doing good with the other topics). Samukan jud kog proving mag nosebleed ko (I got troubled in doing proving, as I start nose bleeding. Soooooorry jud kayo Sir! (Sorry Sir!)" [RF2]

A similar situation on the pretest can be observed in the proof writing of student RM5 in Figure 8. The student has learned the concepts and he tried his very best to come up with the statements and the implications of his statements and but his score is still 0 because his starting statement is stated incorrectly. However, his posttest proving task showed a remarkable improvement as evidenced in a perfect score of 5. This is because the student started his assumption correctly, followed by the implications of his statements, and finally he was able to arrive at the contradiction of the given statement which is shown in Figure 9. It can be seen in proof-writing construction that a student develops an initial negative reactions but after the treatment was introduced that student has developed a positive attitude towards proving. Below are statements on his initial reactions:

"When our teacher asked us the question to prove, my seatmate started mumbling, whoah proving napud!" For a millions time we are proving again. Sus! lisud ra ba mag prove! (Oh! Its difficult to do proving!). Well, I think it's a normal reaction. After a while I started thinking. "Maybe deep inside my heart, a burning heart resides. A heart wanting to break through the barrier of math. I can do this! Because I know deep inside of me, no fear! [RM5]

Consider some proving tasks of student DF1, as shown in Figures 10 and 11. Both pretest and posttest scores of student DF1 get a 0 . This shows that student has tried her best to write her statements but she started with an incorrect assumption and visualized the figure as an equilateral triangle. Her statement, "Suppose $\angle A \cong \angle B \cong \angle C$." is an incorrect assumption. Her succeeding statements are stated incorrectly. Her proof construction in Figure 11 is an evidenced that the student has not understood the logical sequence of her statements in proof-writing construction, even if the treatment or the use of Geometer's Sketchpad on abstract concepts activities were introduced in the class. This student also expressed her opinion that she did not like proving tasks because it gives her headache. Her evaluation response when she was asked to write her initial reactions on the statement "Prove the following statements" is:

"Every time my teacher tells us to prove the following it's like my soul departs from my body, ugh! I hate proving. I never really got the hang of it. I'm also kind of lazy when it comes to critical thinking. My head would burst Prove was the thing I feared most when began my second year life. I have to memorize theorems, postulates, properties, I feel melting". [DF1] 
Figure 6: Proof of an isosceles triangle constructed by RF2 (pretest)

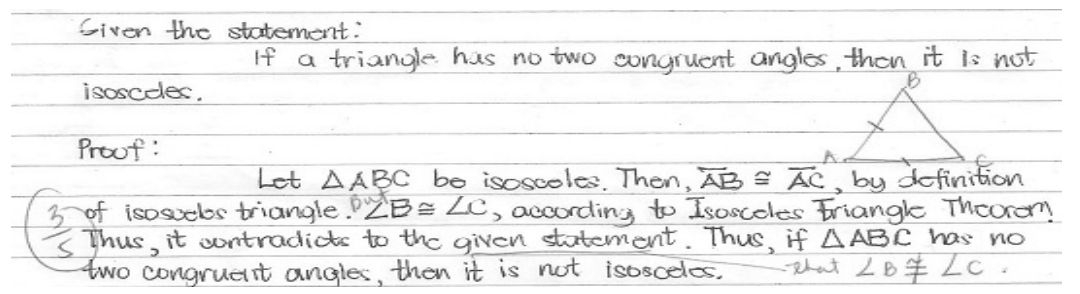

Figure 7. Proof of isosceles triangle constructed by RF2 (posttest)

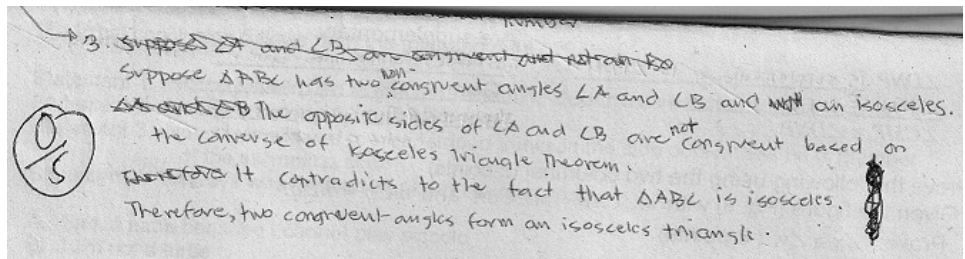

Figure 8: Proof of isosceles triangle constructed by RM5 (pretest)

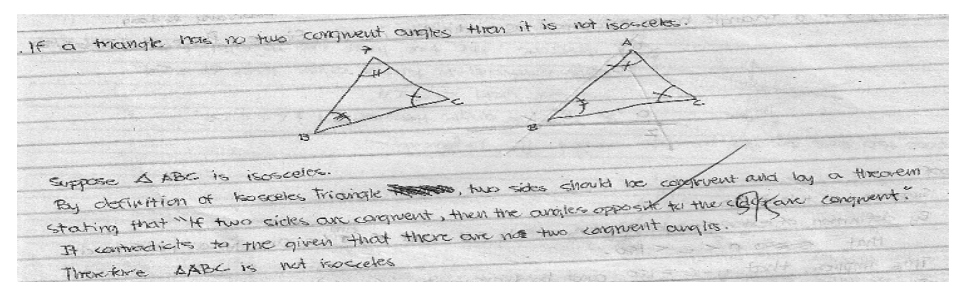

Figure 9: Proof of isosceles triangle constructed by RM5 (posttest)

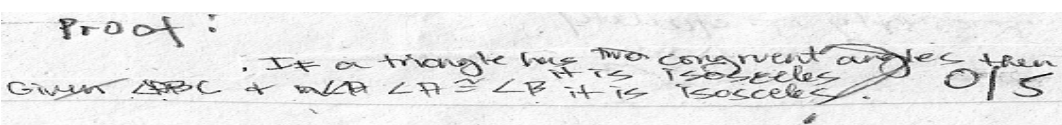

Figure 10: Proof of isosceles triangle constructed by DF1 (pretest) 


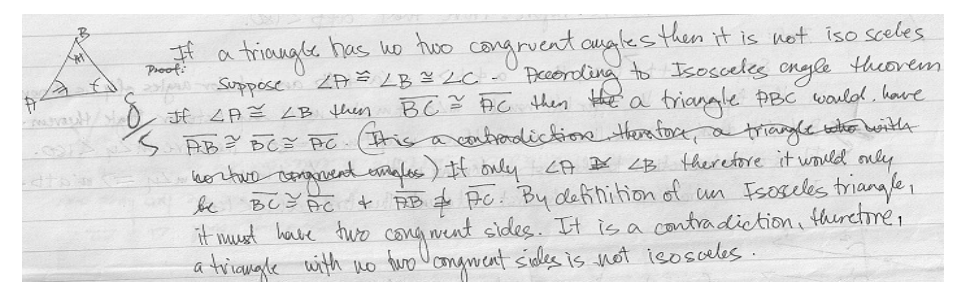

Figure 11: Proof of isosceles triangle constructed by DF1 (posttest)

Other responses of the students as reflected on their written evaluation regarding their initial reactions on the statement "Prove the following statements" yielded the following:

"I don't like proving. It is really my weakness in geometry. I am really confused of what to do. I'm starting to think of the postulates and theorems to use and I find it hard how to start the proof and end my statements and also the flow of proof. When we were asked to prove some statements, I become nervous that I will have a hard time proving it, so I just tell myself, write whatever you know". [RF5]

"I always think, Hoo my God! Here we go again. Whenever there is something to prove, I admit and know nothing about proving". [KF1]

"I find difficult on all its aspect of proving. Because it's difficult to prove. I curse the person who invented proving. Ahhh! "[DM1]

"When I hear the words "Prove the following statements" from our teacher, it always remind me of a man having a nosebleed. Even though it is a "nosebleed" It is fun in a way that we may learn something useful for this subject, with Sir Omeng's jokes, it is a lot of fun." [RM4]

"I'm going to be insane. Proving is very difficult. Memorizing all those stuffs like theorems, postulates and equations would make me insane. But I tried my best to study those stuffs to have a good grade. Now, I'm not worried anymore to do some proving. Now I understand how to prove those statements. Thanks"[KM1].

\section{Using direct proof method and students feedback}

The students were made to prove a problem on basic proportionality which was the third task. They were required to use the direct proof. Results of the frequency distribution of their scores for both pretest and posttest are shown in Table 4. The pretest results show that $31.8 \%$ of the student gets a score of 0 , while $50 \%$ gets a score of 1 . The results suggest that most of the students of this problem task have answered correctly the given or assumptions with score 1 and the rest of the students has stated the assumptions incorrectly with score 0 . In the posttest only $9.1 \%$ gets a 0 score and $2.3 \%$ gets a perfect score. Majority (43.2\%) gets a score of 1 , which is closely followed by 27.35 with a score of 2. By comparing the posttest and pretest in Table 6 , the percentage of students who gets a score of 1 has dropped by $6.8 \%(50 \%-43.2 \%)$; the percentage of the students who gets a score of two has increased by $13.7 \%(27.3 \%-13.6 \%)$; and the percentage of students who gets a score of 3 has also increased by $9.1 \%(11.4 \%-2.3 \%)$. This increase of their performance in proof-writing is the effect of their learning, particularly, in the proving tasks. The students' understanding of geometry concepts has improved and has helped the 
students much because of the integration of Geometer's Sketchpad in the process of learning the subject.

Table 4. Frequency distribution of the pretest and posttest scores in proof-writing on basic proportionality

\begin{tabular}{lcccc}
\hline Score & \multicolumn{2}{c}{ Frequency } & \multicolumn{2}{c}{ Percentage } \\
& Pretest & Posttest & Pretest & Posttest \\
\hline & & & & \\
0 & 14 & 4 & 31.8 & 9.1 \\
1 & 22 & 19 & 50.0 & 43.2 \\
2 & 6 & 12 & 13.6 & 27.3 \\
3 & 1 & 5 & 2.3 & 11.4 \\
4 & 1 & 3 & 2.3 & 6.8 \\
5 & 0 & 1 & 0 & 2.3 \\
Total & 44 & 44 & 100 & 100 \\
& & & & \\
\hline
\end{tabular}

Students' capability to prove in the pretest can be observed in Figures 12 and 14, respectively. Student RF5 shows her proof by using the two-column proof presentation as shown in Figure 14. Her first statement which should be the assumption or given is stated incorrectly. The statement $\frac{A B}{A D}=\frac{A C}{A E}$ should be shown as the problem and not stated as a given. Hence, student RF5 gets a score of 0, while student RF3 shows a paragraph form presentation. She is able to state the assumption ( $\triangle A B C$ and $\overline{D E} / / \overline{B C}$ ) that has a resulted in her getting a score of 1 in the pretest (Figure 14). But the succeeding statements are incorrect, although she has known what is to be proven.

The introduction of Geometer's Sketchpad had enhanced the learning of the students in geometry especially in the aspect of proof-writing. This is evidenced in students RF5 and RF3 who have scores of 3 in the posttest as shown in Figures 13 and 15. Both students construct their analysis by redrawing the figures though they still fail to correctly write succeed the required complete proof.

Figures 16 and 17 show the proof constructed by student RM7 in the pretest and posttest, respectively. It can be seen in Figure 16 that a student gets a score of 0 with a slight improvement of his score 2 in the posttest.

Below are some written responses of students regarding the use of Geometer's Sketchpad which improved students' learning and visualization on abstract concepts:

"When Geometer's Sketchpad (GSP) was introduced it motivates me to improve my performance particularly in proving. The GSP can be manipulated easily. It can measure the lengths and angles. It can construct lines, rays, segments, parallel lines, perpendicular lines, angle bisectors, midpoints and other geometric figures by just clicking on the tool 
bars and menu bars. With this GSP we can easily prove statements given by our teacher". [ RF5]

"GSP helps me, especially my grades are low. It helps me to improve my geometric thinking skills because it teaches me many things like doing some activities. It gave me patience in doing proof'.[RF3]

"This software helped me visualize my geometry thinking skills, with accurate measurements and understandable commands. This software made my knowledge broad and gives me additional knowledge of the subject". [RM7]

"When GSP was introduced in the classroom, it really motivated me to improve my grade, particularly some topics in proving. The GSP measures an actual measurement of angles, length of segments, arcs, diagonals and others which help me to prove the right statements and compare, and observe some situations. It helps me to relate and prove a problem".[KF4]

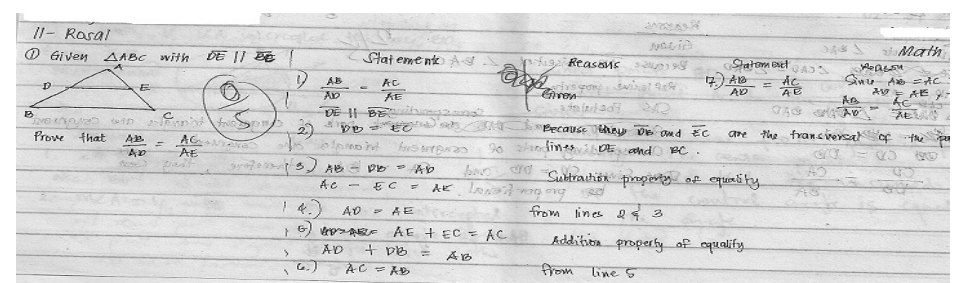

Figure 12. Proof of basic proportionality constructed by student RF5 (Pretest)

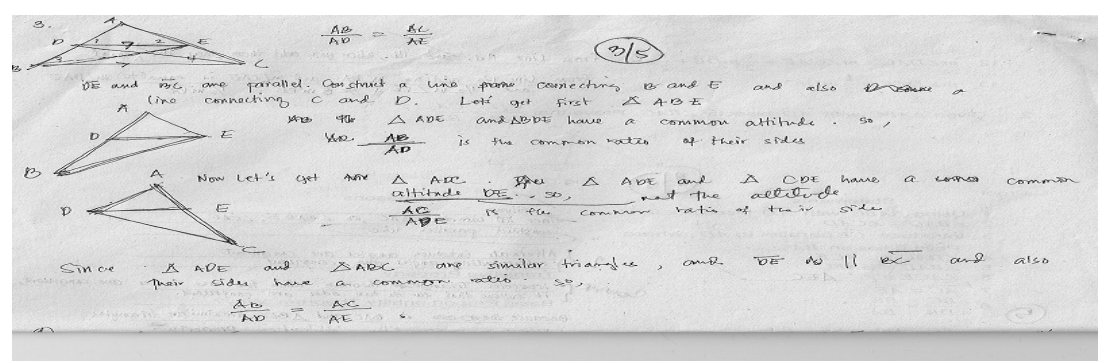

Figure 13. Proof of basic proportionality constructed by student RF5 (Posttest)

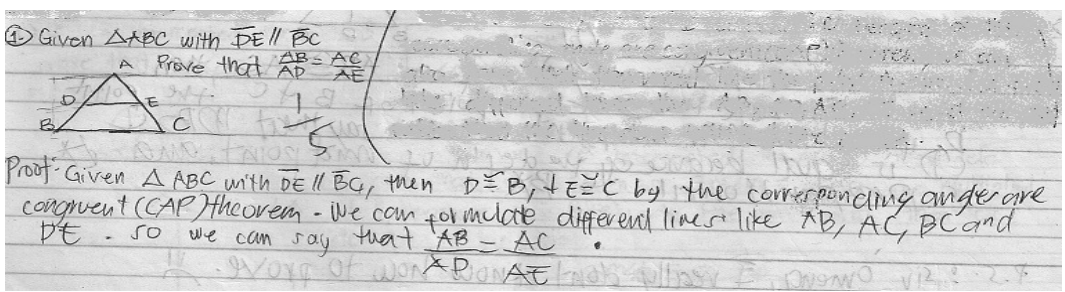

Figure 14. Proof of basic proportionality constructed by student RF3 (Pretest) 


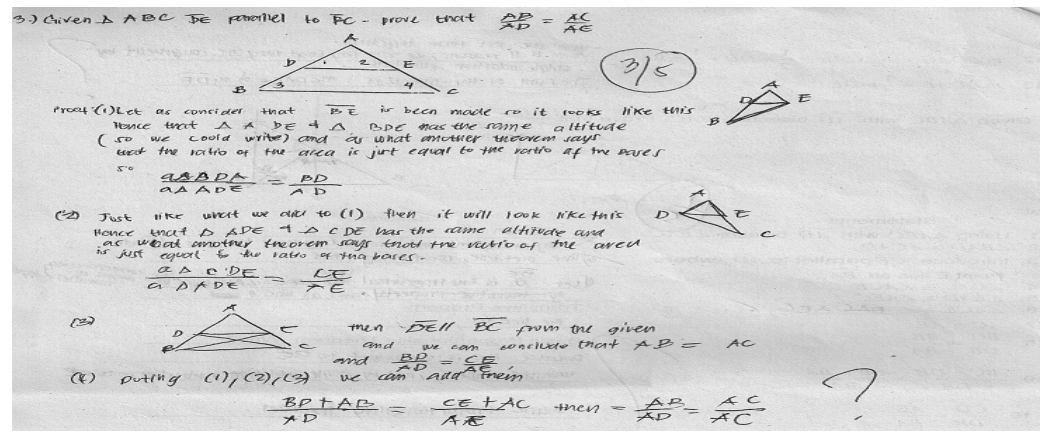

Figure 15. Proof of basic proportionality constructed by student RF3 (Posttest)

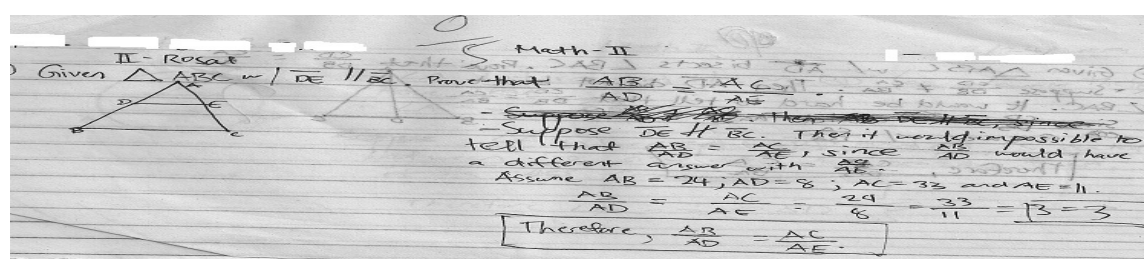

Figure 16. Proof of basic proportionality constructed by student RM7 (Pretest)

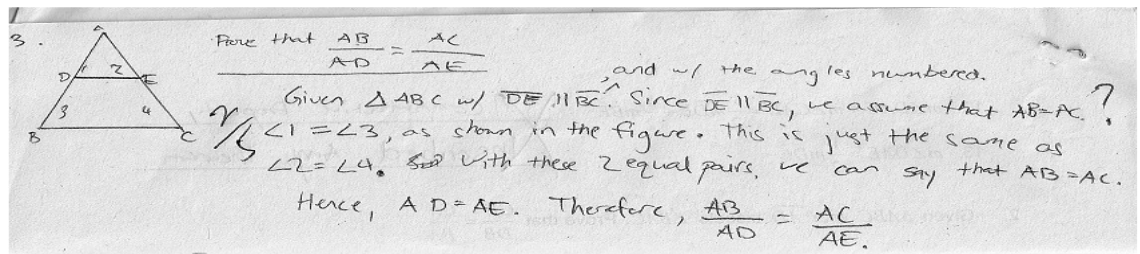

Figure 17. Proof of basic proportionality constructed by student RM7 (Posttest)

The 4th proving task of direct proof is on the quadrilateral within the quadrilateral. It can be seen in Table 5 that most of the students or $63.6 \%$ gets a score of 1 in the pretest. This means that students can write the correct given in the problem. This is followed by $36.4 \%$ with a score of 0 . The score 0 implies that the student cannot state correctly the given in the problem. None among the students gets a score of 2, 3, 4 or 5. However, in the posttest, majority of the students or $13.4 \%$ gets a score of 1 but $13.6 \%$ still gets a score of $0,31.8 \%$ gets a score of 2 , while $9.1 \%$ gets a score of 3 and two gets a score of 4 and 5 , respectively. The students who get a score of either 0 or 1 constitute $50 \%$ of the total number of students who were the subjects of the study. They could hardly identify the given conditions in a given statement to be proved. The other $50 \%$ is able to state the given correctly and has given at least two implications. Their works are similar to the proofs of students RM6 and DM4 in the pretest that are shown in Figures 18 and 20, respectively. Figure 18 shows that student RM6 fails to state correctly the assumptions, given that $\mathrm{ABCD}$ is a quadrilateral and points $\mathrm{E}, \mathrm{F}, \mathrm{H}, \mathrm{G}$ are the midpoints of segments $\mathrm{AB}$, $\mathrm{BD}, \mathrm{DC}, \mathrm{AC}$, respectively. This suggests that the student has no knowledge about the assumptions in the problem. While student DM4 (Figure 20) is able to state correctly the given, using the two-column proof. But he has not succeeded in his task because he lacks the concepts which will help him to proceed and complete the proof. 
Table 5. Frequency distribution of the pretest and posttest scores in proof-writing on quadrilateral within quadrilateral

\begin{tabular}{lcccc} 
Score & \multicolumn{2}{c}{ Frequency } & \multicolumn{2}{c}{$\begin{array}{c}\text { Percentage } \\
\text { Posttest }\end{array}$} \\
& Pretest & Posttest Pretest & \\
\hline 0 & 16 & 6 & 36.4 & 13.6 \\
1 & 28 & 16 & 63.6 & 36.4 \\
2 & 0 & 14 & 0 & 31.8 \\
3 & 0 & 4 & 0 & 9.1 \\
4 & 0 & 2 & 0 & 4.5 \\
5 & 0 & 2 & 0 & 4.5 \\
Total & 44 & 44 & 100 & 100 \\
\hline
\end{tabular}

The posttest proofs constructed by students RM6 and DM4 on the same problem about quadrilateral are shown in Figures 19 and 21, respectively. Student RM6 has not performed well in proof-writing task. It can be seen in Figure 19 where he redraws the figure, labels the figure and locates the midpoints of the segments. But he has not written anything on the concepts he has learned; only the word "none" was written in his test paper which means there is no answer to this problem. The student has expressed his opinion verbally that he was already tired of thinking of the answers of the remaining items. His concerns or problems with geometric concepts and definitions can be derived in his statements:

"Some problems are hard to solve and makes me dizzy and sleepy. I'm tired of memorizing definitions and theorems". [RM6]

Obviously, student RM6 does not have any drive to pursue the proving task. It made him tired, dizzy and sleepy recalling the definitions and theorems. Thus, this student is not interested anymore to do the task. On the other hand, analysis on the proof of student DM4 (Figure 21), shows that he is able to state correctly the assumptions. Given ABCD is a quadrilateral and points $\mathrm{E}, \mathrm{F}, \mathrm{H}, \mathrm{G}$ are the midpoints of segments $\mathrm{AB}, \mathrm{BD}, \mathrm{DC}, \mathrm{AC}$, respectively. He has also proceeded by introducing the diagonals of the figure and has cited the line postulates. He further states the implications of the assumptions and supports his reason by the midline theorem. He has also made his own drawing and has come up with the synthesis by supporting it, by the transitivity property. Although the student has already the idea, he still needs to improve and organize correctly his proof-writing skills. Despite the observed weakness, he has managed to write the conclusion correctly. However, in the sequencing of his proof, it is very evident that he lacks the correct logical sequence connection of the concepts. Below are his statements concerning the problems on geometry concepts:

"Problems in geometry are difficult to solve. In proving for me the hardest part is the sequencing of ideas because I usually forgot what theorems should be used in order to derived another or go to the next step of the way of getting result. Usually I don't know what to write for the next statements". [DM4]. 


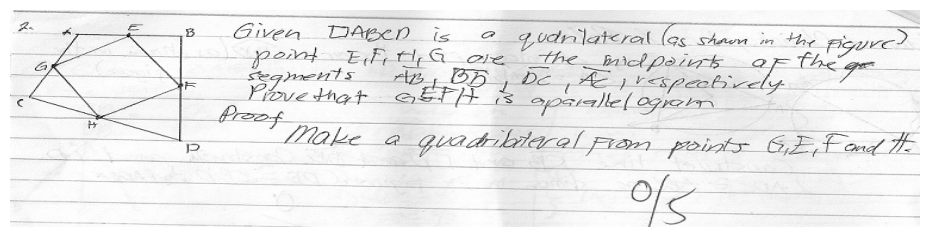

Figure 18. Proof quadrilateral within quadrilateral constructed by student RM6 (pretest)

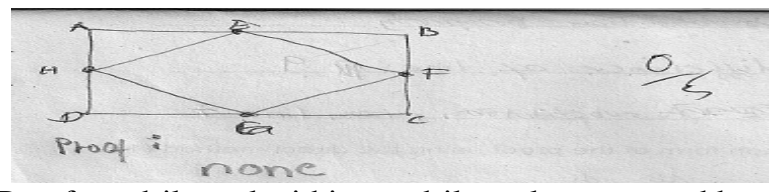

Figure 19. Proof quadrilateral within quadrilateral constructed by student RM6 (posttest)

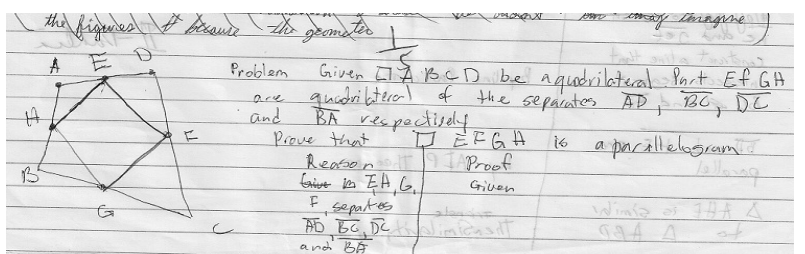

Figure 20: Proof of Quadrilateral within quadrilateral constructed by DM4 (pretest)

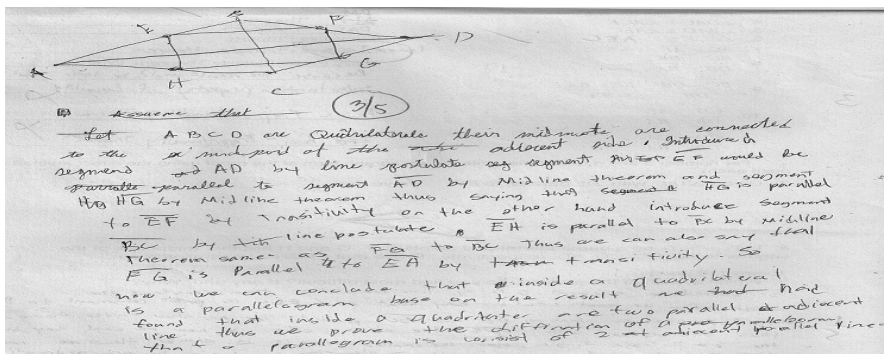

Figure 21: Proof of Quadrilateral within quadrilateral constructed by DM4 (posttest)

Students van Hiele and proof-writing before and after using Geometer's sketchpad It can be gleaned in Table 6, that student mean score of the van Hiele levels of understanding before instruction with Geometer's Sketchpad is only 2.12 while in the posttest is 2.62. When the mean difference was analyzed using the t-test of dependent samples, it yielded a probability value of 0.006 which is significant at 0.05 level. This implies that with Geometer's Sketchpad has enhanced students van Hiele levels of understanding. The same table also show that pretest score in proof-writing, 2.80. After instruction with Geometer's sketchpad activities, the posttest score is even higher than the posttest of the van Hiele levels of understanding test. The difference which is 4.54 was analyzed using the t-test of dependent sample yielded a t-value of 12.24 with a probability of 0.000 . Hence, the null hypothesis is rejected. This suggests that the use of Geometer's 
Sketchpad can enrich the proof-writing skills of the students. This activities would allow the student to construct figures, give measurement of angles and length of segments, relationship and helped the students improved their skills in proving.

Table 6. The Students van Hiele Levels of Understanding and Proof-Writing Before and After Using the Geometer's Sketchpad at T-value

\begin{tabular}{lll}
\hline $\begin{array}{ll}\text { Variables } \\
\text { Pvalue }\end{array}$ & Mean & Mean t-value \\
& & Difference \\
\hline
\end{tabular}

$\begin{array}{ccccc}\begin{array}{c}\text { Van Hiele levels of } \\ \text { understanding } \\ \text { Pretest } \\ \text { 0.006* }\end{array} & 2.12 & 0.808 & 0.50 & 2.938 \\ \begin{array}{c}\text { Posttest } \\ \text { Proof -Writing } \\ \text { Pretest } \\ \text { 0.000* }\end{array} & 2.62 & 0.779 & & \\ \text { Posttest } & 2.80 & 1.82 & 4.54 & 12.24 \\ & 7.34 & 2.85 & & \end{array}$

Note: * - Significant at $\alpha=0.05$

\section{Conclusion}

The following conclusions are drawn based from the research findings:

(1)The Geometer's Sketchpad has influenced the improvement of the van Hiele levels of understanding of students from abstract level of thinking to deductive level of thinking. (2) Proof-writing constructions of the students have overcome their negative feelings and attitude after the Geometer's Sketchpad was introduced in the classroom. (3) Understanding of concepts and logic of students as the source of their proving difficulties is surmounted by introducing Geometer's Sketchpad in the classroom instruction. (4) Exposure to Geometers Sketchpad to students has motivated them to learn and understand the subject matter. It has also improved the students' visualization on geometric concepts and proving abilities that cause the students' to write the correct assumptions and of at least one implication of the assumptions of the given conditions of the problem.

(5) Proof- writing constructions of the students have improved significantly from pretest to posttest after the exposure of the treatment.

\section{References}

Antonini, S. and Mariotti, M.A.(2006). Reasoning in an absurd world. Difficulties with proof by contradiction. Proceedings of the $30^{\text {th }}$ Conference of the International Group for the Psychology of the Mathematics Education, Praque, Czech Republic vol. 2, pp. 6572.

Canoy, Sergio R. Jr. (2007). Difficulty in writing mathematical proofs: An analysis. Doctoral dissertation, Mindanao Polytechnic State College. 
Choi-Koh, S. (1999). A student learning of geometry using the computer. Journal of Educational Research, 92(5), 301-311.

Day, R. et al. (2009) Teaching Geometry, Mathematics Teachers, September Issue, no. 2, vol. 103.

Ding, L. and Jones, K. (2006) Students' Geometrical Thinking Development at Grade 8 in Shanghai. Mathematics Teacher.

Dubinsky, Ed (2000). Towards a of learning advanced mathematical Concepts.

Proceedings of the Ninth International Congress on Mathematical Education, Makuhari Japan, pp 121-123.

Eisenberg, T. and Dreyfuss, T. (1991). On the relevance to visualize in mathematics: Visualization in learning and teaching mathematics. American Mathematics Association, No. 19, pp. 15-28.

Fitzgerald, J. (1996). Proof in mathematics education. Journal of Education no. 78, pp.35-45.

Hedegaard, M. (2002). Learning and child development, Sarhus Denmark, Sarhus University Press.

Hoffer, A. (1981) Geometry in more than proof. Mathematics Teachers, vol. 74, pp. 11-18 (Cited from Choi-Koh).

Hollebrands, K. (2007). The role of a dynamic software program for geometry in the strategies high school mathematics students employ. Journal for research in mathematics education (National Council of Teachers of Mathematics), vol. 38, no. 2.

Jackiw, N. (2001). The Geometers Sketchpad (Version 4.0) [Computer Software].

Emeryville, CA: Key curriculum Press (Cited from Hollebrands).

Knight, K. (2006). An investigation into the change in van Hiele level of understanding geometry of pre-service elementary and secondary teacher. Mathematics Teacher.

Mariotti, M.A. (2000). Introduction to proof: the mediation of a dynamic software environment, Educational Studies in Mathematics v. 44, 25-53.

Mariotti, M.A., Bartolini Bussi, M., Boero, P., Ferri, F., Garuti, R. (1997), Approaching geometry theorems in contexts: from history and epistemology to cognition, Proceedings of the $21^{\text {st }}$ PME Conference , Lathi Findland vol. 1, 180-195.

National Council of Teachers of Mathematics (1989). Curriculum and Evaluation Standards for Teaching Mathematics. Reston, VA: National Council of Teachers of Mathematics .

Ongcol, E.A. (2006). The impact of geometer's sketchpad on the third year high school students'achievement scores in geometry. A terminal Report Presented on Filipino Overseas Department of Education Philippines.

Ross, K. (1998) Doing and Proving . The place of algorithm and proofs. School Mathematics.

The American Mathematical Monthly, pp. 252- 255.

Senk, Sharon L. (1989). Van Hiele Levels and Achievement in Writing Geometry Proofs. Journal of Research in Mathematics Education. Vol. 20, no. 3.

Seeley, C. (2004). NCTM News Bulletin. October issue vol. 41.

Tan, J (2008). Van Hiele levels and achievement in geometry of Central Mindanao University laboratory high school sophomores at CMU (masteral paper, mathematics education), Central Mindanao University.

Usiskin, Zalman. (1982) Van Hiele Levels and Achievement in Secondary School Geometry.

Department of Education, The University of Chicago. Retrieved 2008 from http://socialscience.uchicago.edu/ucsmp/van Hiele_levels.pdf. 


\section{Appendix 1. Problems on proof-writing}

Use proof by contradiction to prove items 1 and 2 .

1. Angle-Sum Inequality: If the angles of a triangle have measures as indicated below, then $a+b<180$.

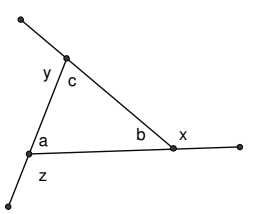

2. Isosceles Triangle: If a triangle has no two congruent angles then it is not isosceles.

Use direct proof to prove items 3 and 4.

3. Basic Proportionality: Given $\triangle A B C$ with $\overline{D E}$ parallel to $\overline{B C}$ as constructed in the figure below.

Prove that $\frac{A B}{A D}=\frac{A C}{A E}$.

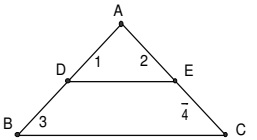

4. Quadrilateral Within Quadrilateral: Let ${ } A B C D$ be a quadrilateral and points $\mathrm{E}, \mathrm{F}, \mathrm{G}$ and $\mathrm{H}$ be the midpoints of the segments $\mathrm{AB}, \mathrm{BC}, \mathrm{CD}, \mathrm{AD}$, respectively. Prove that EFGH is a parallelogram.

\section{Appendix 2 . Students' feedback evaluation}

1. What was your initial reaction/s or feeling/s or idea/s when your teacher asked you to "Prove the following statements".

2. When Geometer's Sketchpad was introduced in the classroom by your teacher, does it motivates to improve your grade or performance in geometry specially in the aspect of proving?. Why? or why not?

3. Does the geometer's sketchpad help you develop or improve or visualize the geometric thinking skills? Why? Or why not?

4. What are some of your concerns or problems, if any, with geometric concepts and definitions?.

5. Which aspect of the proving do you find most difficult? If any and Why? 